\title{
Moral Responsibility for Environmental Problems-Individual or Institutional?
}

\author{
Jessica Nihlén Fahlquist
}

Accepted: 3 November 2008/Published online: 22 November 2008

(C) The Author(s) 2008. This article is published with open access at Springerlink.com

\begin{abstract}
The actions performed by individuals, as consumers and citizens, have aggregate negative consequences for the environment. The question asked in this paper is to what extent it is reasonable to hold individuals and institutions responsible for environmental problems. A distinction is made between backward-looking and forwardlooking responsibility. Previously, individuals were not seen as being responsible for environmental problems, but an idea that is now sometimes implicitly or explicitly embraced in the public debate on environmental problems is that individuals are appropriate targets for blame when they perform actions that are harmful to the environment. This idea is criticized in this paper. It is argued that instead of blaming individuals for performing actions that are not environmentally friendly we should ascribe forwardlooking responsibility to individuals, a notion that focuses more on capacity and resources than causation and blameworthiness. Furthermore, it is important to emphasize that a great share of forward-looking responsibility should also be ascribed to institutional agents, primarily governments and corporations. The urge to ascribe forward-looking responsibility to institutional agents is motivated by the efficiency aim of responsibility distributions. Simply put, if responsibility is ascribed to governments and corporations there is a better chance of creating a society in which the opportunities to act in an environmentally friendly way increase.
\end{abstract}

Keywords Individual responsibility - Environmental problems · Ethical consumers · Forward-looking responsibility · Institutional responsibility

\footnotetext{
J. N. Fahlquist

Department of Philosophy, Delft University of Technology, P.O. Box 5015,

2600 GA Delft, The Netherlands

J. N. Fahlquist $(\bowtie)$

Department of Philosophy, Royal Institute of Technology, Teknikringen 78 B,

10044 Stockholm, Sweden

e-mail: j.a.nihlen-fahlquist @tudelft.nl
} 


\section{Introduction}

Ever since the damage done to the environment came to the fore as one of the modern world's most urgent problems, discussions concerning who causes it and whose task it is to solve it have been frequent. ${ }^{1}$ Both are questions about responsibility, backward-looking and forward-looking responsibility. This kind of discussion has become even more prevalent during the last years when the alarms of climate change have become more recurrent. To what extent are environmental problems the responsibility of individuals, as consumers and citizens? With the knowledge we have today about the causes of environmental problems ${ }^{2}$ and the fact that citizens in many industrialized societies are wellinformed about their own role in contributing to the problems, individuals appear to have some responsibility. People choose to behave in ways that contribute to the problems or to their solutions. Hence, as individuals we are taken to be morally responsible for environmental problems. It has been pointed out that the notion of the consumer as an active and responsible agent is embraced by strong actors within governments, the corporate sector, and NGOs. ${ }^{3}$ Furthermore, it is believed that we can make a difference when making choices about what to buy, and the individual consumer is often seen as not only responsible for herself, but directly responsible for the world. ${ }^{4}$ As Michele Micheletti asserts, "everyday choices and acts by individuals play an important role for the future of political, social, and economic life. In short, every person is part of global responsibilitytaking. ${ }^{5}$ Eivind Jacobsen and Arne Dulsrud, criticize this idea of a "generic active consumer" and claim that this is far from a universal entity. ${ }^{6}$ They argue that consumers appear to be strongly influenced by cultural, social, and institutional settings and thus have very different attitudes and beliefs depending on where they live. This means that the voluntariness with which individuals, as consumers and citizens, act is not as substantial as is sometimes assumed.

These insights should be used in our discussion of individual moral responsibility for environmental problems like climate change. A common assumption is that we are responsible to the extent we causally contributed to a problem. This notion has previously led to the view that because my actions are so marginal, I am not at all responsible for the aggregate environmental problem, e.g., air pollution, the problem of waste, or climate change. This, I believe, is not correct. However, replacing the idea that individuals are exempted from responsibility for environmental problems with a notion of full individual responsibility is too hasty. I will argue that the extent to which individuals should be held responsible for environmental problems needs to be placed in context. More specifically, I will argue that an individual should not necessarily be held responsible in the backwardlooking sense. This means that she should not be blamed for, e.g., performing the less

\footnotetext{
1 In the following, I will use "moral responsibility" and "responsibility" interchangeably.

2 As pointed out by an anonymous reviewer, there are both natural-scientific and institutional causes of environmental problems. Using climate change as an example, the agreement on the natural-scientific causes is substantial. Since the latest IPCC Report (Fourth Assessment Report Climate Change 2007 Synthesis Report http://www.ipcc.ch.), there is even agreement that human beings cause climate change through extensive carbon dioxide emissions. There is more disagreement concerning institutional features that contributes to the problem or its solution.

3 Jacobsen and Dulsrud (2007, p. 475).

4 Sassatelli (2006, pp. 233-234).

5 Micheletti (2003, p. 2).

6 Jacobsen and Dulsrud (2007).
} 
environmentally friendly action instead of the more environmentally friendly action, when she lacked reasonable alternatives or the cost of choosing the right action was too high. The individual's choice to act in a certain way should be considered in her socio-economic, political, and cultural context. The idea that agents should be excused in circumstances when their actions were not fully voluntary has been asserted by philosophers since Aristotle. ${ }^{7}$ However, this reasonable idea appears not to be taken fully into account in the current public debate on individual responsibility for environmental problems. Although it is a good development that we are now starting to publicly debate environmental problems to a previously unseen extent and to acknowledge the role of human beings, we now seem to run the risk of putting too much focus on the behavior of individuals at the expense of illuminating the vital role of institutions.

Although sometimes excused from backward-looking responsibility, I will argue that some individuals should be ascribed forward-looking responsibility. Individuals who have reasonable alternatives, capacity, and resources to do something about the environment should be seen as responsible. Institutional agents have the power and resources to affect the number of individuals who possess such capacity and resources. Because of this, a great share of responsibility should be assigned to governments and corporations. I will argue that such institutional agents are responsible (in a forward-looking sense) because a) they have power and resources to do more to solve environmental problems, and b) they have the capacity to make it easier and less costly for individuals to act in environmentally friendly ways.

Before moving on, let us make two conceptual clarifications. First, when I discuss individual responsibility in the following, I primarily refer to individuals as individual consumers and/or citizens. I will not discuss individuals acting in groups, nor will I discuss group agency. Those are interesting questions, but they will not be the focus of this particular paper. Second, when I discuss institutions or institutional agents I primarily refer to governments and corporations.

The paper is structured as follows. First, some examples are given to show what I have in mind when discussing individuals being responsible for acts that contribute to environmental problems. Second, the concept of moral responsibility is discussed to clarify the thesis of the paper. Third, the notion that individuals are blameworthy for performing acts that contribute to environmental problems is criticized. Fourth, the suggestion that individuals are responsible in a forward-looking sense is presented. Fifth, the forward-looking responsibility of institutional agents is discussed.

\section{Examples-The Intuitive Level}

Before discussing the issue of responsibility from a philosophical perspective, let us look at a few examples that inspired this paper.

Imagine that in Agnes's residential area, which is socio-economically underprivileged, there is no recycling station and Agnes, who cannot afford to drive a car, would have to travel by public transport to get to the nearest recycling station. Agnes is a single mother and it is practically very challenging for her to take her waste to the recycling station. Her options are as follows.

\footnotetext{
7 Aristotle, Nicomachean Ethics, Book III. Aristotle Nicomachean Ethics The Internet Classicas Archive, translated by W.D. Ross http://classics.mit.edu/Aristotle/nicomachaen.html.
} 
1) Going to the recycling station and putting the cans in the appropriate container. In this case, she has three options:

a. Bringing her three children, paying for bus tickets, and going to the recycling station.

b. Hiring a babysitter, paying for a bus ticke,t and taking the bus to the recycling station.

c. Borrowing someone's car to go to the recycling station.

2) Throwing the cans in the household trash.

If she lived in a place where the recycling station was merely a short walk away or if she had someone who could help her by taking her waste to the recycling station for her or look after her children while she went there, that would have made a difference in terms of her options. "Intuitively, it does not appear reasonable to hold Agnes fully responsible for choosing the second option, i.e., to throw the cans in the household trash."

A second example relates to the suggestion that consumers should choose "climate smart" food over food that has been transported long distances by airplane or truck or the production of which was very energy-intense. Imagine Bernard, a consumer who refrains from buying "climate smart" food. If Bernard is economically under-privileged and lives in a society where organically and locally produced vegetables are more expensive than non-organic tomatoes from far away, then buying "climate smart" products would require much more of him than an individual under more fortunate circumstances. If compared to another individual, Charles, who lives in the same society, but who is well-off, there is obviously a crucial difference between Bernard and Charles in terms of the cost of choosing the environmentally friendly action.

A third example is the notion that we should all contribute to the reduction of carbon dioxide emissions through using public transport instead of driving our own cars. The environmentally friendly thing to do is most probably to take public transport instead of driving a car to work and in some places there are reliable, safe, and well functioning public transport systems. However, other societies lack a reliable, safe, and adequately extensive public transport system and this, my intuition tells me, makes a relevant difference for what can justifiably be required.

Imagine an individual, Donna, who lives in a society where public transport is welldeveloped and another individual Emma, who does not. The crucial difference between Donna and Emma is the alternatives open to them. It is not asking too much to expect Donna to use public transport, thereby contributing to a better environment or at least not polluting it. However, expecting Emma to do the same is to ask a lot more, since the alternative is either not there or is there but the cost of choosing it (in terms of money, time, and/or convenience) is simply too high. Whereas we still believe she should do what she can to use public transport instead of driving a car, we should not put the same kind of demands on her as we do on Donna. The alternatives presented to Emma may be the following.

1) Driving for one hour.

2) Walking five minutes to the subway station and taking the subway to work, which is a one hour journey.

Compare this to Emma's options below.

1) Driving for one hour.

2) Walking 1000 meters to the bus stop, waiting for the bus that is normally not on time and travelling for two hours on the bus. 
We have now looked at some cases in which the environmentally damaging act of an individual is put in the context of the alternatives she had when acting. In the first case the problem is the practical challenges or the effort that has to be made in order to do the environmentally friendly thing. In the second example, the obstacle is money. In the third example it is the infrastructure that is different in Donna's and Emma's cases. The infrastructure is arguably the result of political decisions, culture, and tradition as well as economic factors.

The examples are common in everyday life and I think many of us, if confronted with such examples, would agree that people have different sets of alternatives when acting due to their different contexts and the choice to act in environmentally damaging ways can be more or less voluntary. I argue that this should be taken into account when discussing individual responsibility for environmental problems. I believe many of us share this intuition and many philosophers have theorized about the importance of alternatives for acting and the importance of voluntariness to moral responsibility. Yet this notion is frequently ignored in the public debate on individual responsibility for the environment where all individuals appears to be considered as equally appropriate subjects of responsibility, as if either all individuals are responsible for the environment or no individuals are responsible for the environment.

\section{Moral Responsibility}

Before continuing the discussion, we should make some clarifications regarding the concept and notions of moral responsibility.

The concept of moral responsibility is evasive and is used differently in different contexts. It is sometimes equated with blameworthiness, but whereas blameworthiness was discussed by Aristotle, the term responsibility is fairly new. ${ }^{8}$

A first distinction to be made is the following. First, responsibility can be used in a backward-looking (retrospective) sense and a forward-looking (prospective, remedial) sense, i.e., essentially referring to blameworthiness for past actions or to future action taking. The notion that responsibility is sometimes more forward-looking than backwardlooking is common in non-philosophical discussions, but it is to, some extent, a neglected topic in philosophical discussions. ${ }^{9}$

Traditionally, the primary notion discussed is backward-looking responsibility, or rather backward-looking responsibility as blameworthiness or culpability. The notion of responsibility I question in the following is backward-looking, referring to actions performed by an individual in the past that are believed to have caused negative outcomes and where the agent is considered blameworthy. This idea will be contrasted with a more forward-looking notion of responsibility.

So, what is it to be responsible in the backward-looking sense? According to Peter Strawson's influential theory of responsibility, moral responsibility consists of the reactive attitudes, for example resentment and gratitude, we hold towards each other as co-members of the moral community. ${ }^{10}$

\footnotetext{
${ }^{8}$ McKeon (1957).

9 Some exceptions: Richardson (1999, pp. 218-249); Young (2006), Goodin (1986); Miller (2005); Green (2005), and Nihlén Fahlquist (2006).

10 Strawson (1962).
} 
In our present context this could mean, for example, that when someone who is environmentally aware sees Agnes throwing aluminium cans in the trash bin she is likely to react with some resentment and hold Agnes responsible by blaming her for performing the action that contributes to the problem of waste instead of the action that is more environmentally friendly, i.e., to recycle the cans. ${ }^{11}$

However, the reactive attitudes appear not to tell the whole story of what moral responsibility is. For, as members of the moral community, we also have the ability to step back and analyze situations from a more detached perspective and most of us are also able to assess and alter our conduct, for example when confronted with new information. When the person blaming Agnes learns more about Agnes's situation, she may analyze the situation differently and change her view on Agnes's responsibility.

It has been argued that Strawson's view makes it difficult to criticize practices of holding agents responsible and that it is, to some extent, static and relativistic. There is a difference between being held responsible and being responsible that is not captured by the theory of responsibility as reactive attitudes. ${ }^{12}$ To be morally responsible is not merely to be a target of reactive attitudes. According to John M. Fischer's revised Strawsonian theory, "agents are morally responsible if and only if they are appropriate recipients of reactive attitudes." ${ }^{13}$ Hence, whereas one element of moral responsibility is the reactive attitudes towards the actions of co-agents in a moral community, another element is critical reflection of these practices.

Thus, the notion being criticized in this paper is the following.

Individuals, as consumers and/or citizens are appropriate recipients of reactive attitudes, e.g., blame, when acting in ways that, in the aggregate, contribute to environmental problems.

\section{Individuals and Blameworthiness}

Previously, environmental problems were not thought to create demands for individuals, but instead these problems were merely discussed on an international level by governments as a matter of legislation and policy and for a long time the environment had a low priority. This approach, I think, was too extreme in its refusal to acknowledge individual responsibility. It was too extreme for two reasons. First, if we are to solve environmental problems, which we should, it will in the end be a matter of people acting in ways that promote such solutions. The question is how to get there, not whether we should get there. Second, a society in which people care about the environment, perhaps by developing green virtues, ${ }^{14}$ is likely to be a better society. I will not go into the arguments here, just state that those who claim that individual behavior is important as well as those arguing that a society where people care about the environment is better than a society where people do not care about the environment appear to have reliable arguments. I will not dig deeper into that here because I would like to focus on the current tendency in the public debate on environmental problems, primarily climate change because of its urgency, to ascribe responsibility to individuals as consumers and citizens for those problems. To make

\footnotetext{
${ }^{11}$ I assume here that this is the more environmentally friendly act, being aware that there may be different opinions on that.

12 Fischer and Ravizza (1993).

13 Ibid.

14 Jamieson (2007).
} 
this clearer, I do not disagree with those who claim that it is ultimately a matter of individuals behaving in ways that promote a better environment. I wish to question the jump from that observation to the conclusion that individuals are blameworthy for acts that contribute in the aggregate to environmental problems.

During the last few years, when climate change has come to the fore as the major global challenge and is beginning to be discussed as a moral issue, individuals are increasingly seen as the responsible agents and appropriate targets of blame when refraining from acting in climate-smart ways, e.g., recycling, turning the thermostat down, driving a car instead of using public transport or cycling and so forth. Accordingly, demands that individuals' choices regarding, for example, consumption and transportation should be morally scrutinized are being expressed in public debates. There are, for instance, tests on various websites where one can answer a set of questions to see how "climate-smart" one lives, whether one is "environmentally aware" and so forth. Consumers who buy organic (and fair trade etc.) food are called and sometimes identify themselves as "ethical consumers." The implicit implication of this new notion of full individual responsibility for the environment appears to be that if one does not always choose the most environmentally friendly option, one is, to some extent, an "unethical" or at least a "non-ethical" or irresponsible consumer, hence an appropriate target for blame.

The primary problem with the question whether individuals should be held responsible when acting in ways that contribute to environmental problems is that it is often assumed to be a question between the following statements:

1. Individuals should be held responsible when acting in ways that contribute to environmental problems.

2. Individuals should not be held responsible when acting in ways that contribute to environmental problems.

What is not being acknowledged when stating the question as a choice between 1 and 2 is that individuals are different and exist in different socio-economic, political, and cultural contexts. Consequently, the answer cannot be that all individuals are always responsible or no individuals are ever responsible. Individuals are responsible, i.e., appropriate targets of blame, for some of their environmentally-unfriendly actions and not for others. The notion that individuals perform such acts with different degrees of voluntariness should inform our ascriptions of responsibility. This is an old idea that is not adequately taken into account in the current public debate on environmental problems.

The notion that the degree of voluntariness with which an agent performed an act affects the blameworthiness of that agent has been present in philosophical discussions since Antiquity. According to Aristotle, agents are only blameworthy for voluntary acts. Voluntary acts are acts not performed under i) compulsion or ii) due to ignorance. ${ }^{15}$ Whereas individual responsibility (in the backward-looking sense) was for a long time not discussed in debate on environmental problems, we have seen a change during recent years and we are now, as consumers, expected to behave in certain ways, for instance to buy organic food, to use public transport, to ride a bike, and to reduce the thermostat in our houses and so forth. This is problematic partly because when we make claims about what individuals ought to do and what their responsibility is, individuals are taken to be very similar, as if their social, economical, cultural, and political contexts were identical. Eivind Jacobsen and Arne Dulsrud, rightly criticize this idea of a "generic active consumer" and argue that

15 Aristotle, Nicomachean Ethics Book III. 
this individual is far from a universal entity. ${ }^{16}$ Instead consumers appear to be strongly influenced by cultural, social, and institutional settings and thus have very different attitudes and beliefs depending on where they live. However, focusing too much on individual responsibility is not problematic just because individual differences are not acknowledged to an adequate extent. It is also problematic because there are often structural and societal features, that work as obstacles to most citizens in a society.

What I am arguing here is the following. Individuals are blameworthy for acts that contribute to environmental problems, e.g., refraining from recycling, driving instead of using public transport or a bicycle, when it was reasonable to expect them to choose the environmentally friendly option. This means that when there was a reasonable alternative to act in a more environmentally friendly way or when the cost and effort of performing the environmentally friendly act was reasonable an individual is to blame for not choosing that course of action. This is so because when they had that alternative, for example, when there is a highly developed and accessible recycling system, public transport system, or bicycle lanes, it is reasonable to demand that they do choose the environmentally friendly option. Likewise, if the individual is well-off it is reasonable to expect her to buy climate-smart food even if it is expensive. If such opportunities to do right, to act environmentally friendly, exist to an adequate extent there are no excuses and individuals should be expected to do so. However, if an agent is poor and climate-smart food is expensive-it is not fair to hold her responsible for buying the least expensive and less environmentally friendly alternative.

\section{Reasonable Alternatives}

What, then, can be said about the reasonableness of alternatives? When does an individual consumer or citizen have reasonable alternatives? As mentioned above, Aristotle argued that an individual should be excused from (backward-looking, in my terms) responsibility (blame) when she did not act voluntarily, i.e., acted under compulsion or due to ignorance. The lack of reasonable alternatives can be stated in similar terms. Although consumers are not coerced into buying food that was produced using unnecessarily high levels of energy, if organic or climate-smart food is very expensive compared to regular food, the alternative to buy the environmentally less damaging food is not really an option unless the consumer is wealthy. This is an example of how the cost of choosing the "right" option is highly relevant. In addition to cost, the availability of good options is relevant. If $99 \%$ of the products in grocery stores are not climate-smart products, this is obviously an obstacle to people who want to reduce their carbon footprint even if they can afford to buy those products. Similarly, unless there are safe and extensive bicycle lanes, the alternative to ride a bike instead of driving a car is not a realistic option for people who drive to work. The latter is an example of how culture, tradition, and political decisions affect how people choose to act. They may choose to drive their car because they grew up and live in a society that treats cars and highways as very important parts of life and society. On the other hand, they may resist that cultural pressure and want to ride a bicycle or use public transport instead, but if the infrastructure makes it difficult or too inconvenient to choose those options, the conscientious citizen may, very reluctantly, continue to drive their car to work. In real life, compulsion appears to be a matter of degree and although nobody is forcing people, it may be very difficult to choose the environmentally friendly option.

$\overline{16}$ Jacobsen and Dulsrud (2007). 
It is obviously difficult to draw a line between what is reasonable and what is not in individual cases. On the political and general level, it is clear that some infrastructural, cultural, socio-economic, and political features of modern societies are questionable from an environmental perspective and that these features affect what alternatives individuals have to act in ways that promote solutions to environmental problems. The most obvious problem is likely to be the car-dependency of industrialized nations. A second problem may be the extent to which people in Western societies are used to eating meat products. A third problem is the overuse of packaging and plastic bags.

In addition to cost and the availability of good options, information about the environmental footprints we leave is obviously crucial. However, the question of what information there is, is not as straightforward as one might think. In most well-ordered societies there is information available, which means that most people have the opportunity to know how their behavior affects the environment. Even if there is a lot of information, it is sometimes too expensive to do the environmentally right thing. In many cases, the information does not reach all groups of people in society.

Furthermore, all these factors, cost, substantial inconvenience, availability, and information problems, affect the reasonableness of the alternatives individual consumers and citizens have when they "choose" to act in environmentally friendly or environmentally unfriendly ways. Because these are highly prevalent problems in most societies today, it is not fair or fruitful to ascribe backward-looking responsibility neither to individuals taken separately nor to the group of individual consumers or citizens in these societies.

\section{Individual Forward-Looking Responsibility}

To abandon talk about individual responsibility in the backward-looking sense does not necessarily entail an abandonment of all notions of individual responsibility for the environment. There is an additional notion of responsibility that should be used instead. It is common in non-philosophical debates, but less explored in philosophical literature, i.e., forward-looking responsibility. ${ }^{17}$ My claim is that although individuals should not be held responsible in the backward-looking sense when they did not have reasonable alternatives to act in environmentally friendly ways, it is sometimes reasonable to ascribe forwardlooking responsibility to individuals.

So, what is forward-looking responsibility? James Garvey, discussing the claim that rich countries ought to do more than poor countries to combat climate change, suggests that just as "ought implies can" is usually seen as a core principle in ethics, "can implies ought" in some circumstances. ${ }^{18}$ He does not elaborate this idea, but I believe there is something highly reasonable in his brief statement. One of the arguments for the principle Common but Differentiated Responsibilities (CDR) is based on a similar notion. CDR is the principle stating that rich countries should bear a greater proportion of responsibility for climate change. There are two very different justifications for CDR. First, rich countries are said to have a greater responsibility to solve the problems of climate change because they, historically, contributed more to the emissions of carbon dioxide. Second, rich countries have a greater capacity primarily in terms of power and resources to solve these problems. Whereas the former justification is in line with the backward-looking notion of responsibility, the latter is more in line with a forward-looking notion of responsibility. This is a

\footnotetext{
17 Richardson (1999).

${ }^{18}$ Garvey (2008).
} 
reasonable idea and, I would like to argue, should be applied to individuals as well as to nations. If an individual is in a good position to do something to contribute to the solution of environmental problems she has a responsibility to do so. If an individual is less capable to do so, she should be partly excused. There is no standard individual who has a standard share of responsibility, namely full or no responsibility. There are only particular individuals in particular socio-economical, cultural, and political contexts.

The idea that if you have more resources or a greater ability to contribute to a solving a problem is endorsed by many people, although not necessarily explicitly. Consider, for instance, the financial donations to charity made by extremely affluent people like Bill Gates. Of course it could be argued that he does not have to contribute to social causes, but it is admirable that he does so, that he is an altruistic person. Alternatively, it could be argued that he only contributes for PR reasons, i.e., that he wants to market himself as a good or moral person because that is good for business. However, I think many people would describe this as a wealthy, resourceful, and powerful man taking his (forwardlooking) responsibility, a responsibility it is reasonable that he takes because of his capacity to contribute to social causes. At a minimum, to think about it this way does not appear to be tremendously controversial.

The same applies to the idea of Corporate Social Responsibility (CSR), i.e., the discussion concerning whether private companies have a responsibility (extending their legal responsibility) to contribute to social causes or not. If so, should they do it because it is good for business or should they do it regardless of the effect on business or does the reason for doing it matter at all if the consequences are good? Regardless of this debate in business ethics, many people today appear to think that multi-national companies or large companies have a responsibility to contribute to societal causes. A third example relates to the notion that rich countries have a responsibility to help poor countries in various ways, with money, education, and technology transfer. In developed, democratic, and wellordered nations it is a shared notion that the government should give aid to less developed countries. There is often disagreement on the size of aid and the exact content (money or self-help aid), but that there ought to be some kind of aid to less fortunate peoples is now a well-entrenched notion in developed nations.

These discussions are likely to go on and my intention of bringing them to the current discussion is not to go deeper into the arguments for and against the various views. However, these debates show that there is a common intuition in contemporary societies that if an agent, whether individual or institutional, has the capacity, power, and resources to contribute to solving a social problem, they have a responsibility to do so, i.e., that power and capacity entails responsibility. This kind of responsibility is forward-looking and fairly open-ended and it does not have to be stated exactly when such a responsibility has been fulfilled. ${ }^{19}$ Consequently, it leaves open exactly what the agent ought to do and involves a certain degree of flexibility and permission to improvise.

This is the way in which individuals as consumers and citizens are responsible for environmental problems. Individuals should do what they can against the background of their particular situation. The more resources, power, and capacity an agent has the better her ability to contribute to solving the problem and the more reasonable it is to ascribe forward-looking responsibility to her. This view means that the causal links are less central than it is in the backward-looking concept. Just as Bill Gates did not cause the social problems he contributes to solving by giving money to charity, the individuals that are best placed to contribute to solving environmental problems are possibly not the ones who

${ }^{19}$ Goodin (1986); Richardson (1999, pp. 218-249). 
contributed the most causally to these problems. Their position to do more can be due to several factors, most likely involving financial resources but also education, information, and leadership skills in terms of a talent for influencing others.

\section{Institutional Responsibility}

We now have the conceptual and normative tools to say in virtue of what institutional agents like governments and corporations are responsible for environmental problems and how their responsibility is related to individual responsibility. Governments and corporations are responsible because it is in their power to create reasonable alternatives for individuals. They have it in their power to make it easier and less expensive for individuals to choose the environmentally friendly option and they can provide information that is easily accessible and as straight-forward as possible. In essence, they are responsible because they have the power to create opportunities for individuals to do what is right. Another way of phrasing it is to say that institutions can make it easier for individuals to assume forward-looking responsibility. This could be done by making information accessible, subsidizing organic food while taxing non-organic food, by product development and presentation of products and so forth. ${ }^{20}$ The greater the extent to which these actors have done that, the greater the extent of individual responsibility. The greater the extent to which institutional agents have taken their forward-looking responsibility, the greater the extent to which it is reasonable to ascribe both backward-looking and forwardlooking responsibility to individuals when they do not choose the environmentally friendly option. First, the greater the availability and affordability of good options, the more reasonable it is to blame those individuals who still do not adjust their behavior. Second, the greater the extent to which, e.g., governments have assumed their responsibility, the larger the group of individuals with enough capacity and resources to assume their forwardlooking responsibility.

For example, if the government has invested in an extensive public transport system, the degree of individual responsibility for choosing to drive a car instead of using public transport is higher than it would have been if the public transport system had been underdeveloped and unreliable. If a corporation can provide environmentally friendly products at a reasonable cost it is their responsibility to do so. For example, restaurants should be able to provide customers with food that has been produced in environmentally friendly ways and not transported across the globe.

Some critics will argue that individuals have a personal responsibility, which would be eroded if we allocate too much responsibility to institutional actors. Do individuals not have to do anything by themselves? I think there are two ways to respond to such criticism.

First, one way of conceptualizing a forward-looking responsibility is through a virtue ethical approach. Garrath Williams views responsibility as a virtue, which essentially represents a "readiness to respond to a plurality of normative demands." 21 This is a slightly different way to conceptualizing the idea that individuals are too complex to assess morally merely on the basis of isolated actions. Instead focus should be on an individual's whole life and character as well as the way in which the character evolves and improves.

\footnotetext{
${ }^{20}$ Of course it is not always easy to determine whether organic food is the best option from a climate change perspective.

21 Williams (2008).
} 
It focuses on the different roles an individual has and challenges to respond to a plurality of, sometimes even conflicting, demands. Viewed from that angle, personal responsibility is still very important.

However, what should be acknowledged is that individuals' character and the virtue of behaving responsibly can be affected by social systems, policies, and information and education. Against this background, this institutional responsibility can be stated as follows.

Responsibility of governments and corporations: To create systems to make it easier for individuals to respond to the emerging norm that we ought to act in environmentally friendly ways.

A second way of responding to the critique that personal responsibility is eroded if too much responsibility is ascribed to institutions is the following. Ascribing and distributing responsibility is a social practice that serves two purposes. First, it creates or establishes fairness. Second it is a tool to establish an effective and efficient division of labor in order to solve societal problems. ${ }^{22}$ The optimal distribution of responsibility is both fair and effective, although it is sometimes difficult to achieve both to the same extent. Sometimes, one of the two purposes is more important than the other and the two have to be weighed against each other in each case. There are areas of life and society where stating that something is the personal responsibility of individuals is fair and when this is the most important feature of that distribution of responsibility. There are other areas, for example, climate change, the problems of which are too urgent and to vast to only care about fairness and personal responsibility.

The long-term goal should be to encourage virtuous individuals, as citizens and consumers, i.e., for example to have people embrace green virtues. ${ }^{23}$ It would, of course, be nice if people in general start to care about the environment more naturally and every day. However, from the short-term perspective we need to add that this distribution of responsibility should also be effective and efficient, i.e., contributing to a solution to the problem. That is why the greatest share of responsibility for environmental problems should be ascribed to the most powerful, resourceful, and capable actors, i.e., governments and corporations, because they can create systems that make it easier and less costly for people to choose the environmentally friendly option than to choose the environmentally harmful option. As argued by Henry Shue, some duties should be assigned to institutions instead of individuals because that is likely to be more efficient. Institutions can make possible the coordination and cooperation that are needed for those duties to be fulfilled. A second reason is that it would be to demand too much of people to assign such duties to individuals because individuals have rights as well as duties and should be allowed some time outside of their role as duty-bearers. Thus, for reasons of efficiency as well as for reasons of fairness institutions as opposed to individuals should be considered the main duty-bearers. However, this does not mean that individuals are completely exempted. On the contrary, it is their duty to make sure there are adequate institutions to implement the duties in question. ${ }^{24}$

\footnotetext{
${ }^{22}$ Williams 2008 talks about a moral division of labor in a discussion of responsibility as a virtue. According to Williams, the institutional fabric of liberal democratic societies creates a moral division of labor by delimiting spheres of responsibility. For a discussion on fairness and efficiency as two aims of responsibility ascriptions, see Nihlén Fahlquist (2006).

23 C.f Jamieson (2007); Ladd (1991) concerning green and civic virtues respectively.

${ }^{24}$ Shue (1988, pp. 696-698).
} 
Whereas, Shue argues that the role of institutions is to implement the duties, Michael Green argues that the responsibility of institutions is even greater than the responsibility of individuals. He argues that while it is reasonable to keep the restrictive version of responsibility, i.e., the responsibility that always traces behavior to harm for individuals, a more comprehensive kind of responsibility should be assigned to institutions because they constitute a different kind of agent. Institutions have more power and can alter mass behavior, they are better at collecting and processing information about direct and indirect consequences of their actions and they can spread the cost through taxation. Essentially, institutional agents have more capacity; hence a greater share of responsibility is justified. ${ }^{25}$ Similarly, Walter Sinnott-Armstrong argues that whereas individuals do not have a moral obligation not to waste gas, governments have a moral obligation to fight global warming, primarily due to the scale of the problem. ${ }^{26}$

Thus, due to the urgency and scale of environmental problems, it appears a good case can be made to include institutions into the discussion on how to distribute responsibility for such problems. Having said that, the fundamental unit in society is the individual citizen and institutions are created and upheld by individuals acting together. Hence, it appears reasonable to expect individuals with capacity, resources, and knowledge to create environmentally friendly institutions. In addition to voting, this also involves creating, supporting, and joining organizations that work to improve the environment. ${ }^{27}$ This, in turn, could entail different activities, for example working to directly improve the status of the environment, working to improve consumers' options and increase their information, working to raise people's awareness and working to change the more traditional organizations (trade unions, culture and sports associations, and so forth). As argued by SinnottArmstrong, instead of just withdrawing from society and adjusting one's own lifestyle to create as little environmental damage as possible, it is even more important to be proactive and work to change government policies and laws. ${ }^{28}$

\section{Conclusion}

I have criticized the increasing tendency to hold individuals responsible for environmental problems in a backward-looking sense. I have argued that individuals are not appropriate targets of blame when acting in environmentally destructive ways unless they have reasonable alternatives. Today, many individuals lack such options or do not have the resources to do the environmentally friendly thing. Here are just a few general or structural obstacles to individuals in modern societies that make unreasonably difficult to act in environmentally friendly ways.

- The infrastructure in many societies encourages people to drive instead of using public transport or bicycles. Individuals need to drive to the supermarket, to work and to school. If they do not need to drive, it is often easier and/or less expensive to drive than to take the train.

- It is assumed in many industries that people need to meet face to face, hence extensive business traveling.

\footnotetext{
25 Green (2005).

26 Sinnott-Armstrong (2005, p. 304).

27 I would like to thank this journal's Editor-in-Chief for commenting on this.

28 Sinnott-Armstrong (2005, p. 304).
} 
- The information about the origin and energy cost of producing certain consumer goods, e.g., food, is often inadequate.

- Government information is sometimes unclear, or even conflicting. Food products that are encouraged for health reasons are sometimes discouraged from an environmental perspective. $^{29}$

- Climate-smart food is often substantially more expensive than regular food.

These are just a few general structural problems and there are also individual differences that should be taken into account. What options an individual has or the cost of acting in an environmentally friendly way should be seen as interplay between the individual and her surrounding socio-economic, political, and cultural environment.

Although it is questionable to hold individuals responsible in the backward-looking sense, it is reasonable to hold individuals responsible in a forward-looking sense. Again, the different contexts and the different extent to which individuals have the capacity and resources to assume such responsibility should be taken into account. The most important conclusion is that governments and corporations have a great forward-looking responsibility to create opportunities for individuals to behave responsibly and act in environmentally friendly ways. Although acknowledging individual responsibility is beneficial, we should make sure that institutional responsibility is not overlooked or ignored as a consequence.

There are good reasons to argue that responsibility ascriptions and distributions should be both i) fair and ii) efficient. They should be fair for reasons of social cooperation and humanity. Cooperation is easier to achieve in a society where the norm is to hold someone responsible only when it is fair to do so and such a society is arguably more humane. Of course there is no simple answer to the question when it is fair to hold someone responsible. However, it is common both in social practice and philosophical discussions to apply a number of conditions when ascribing responsibility. For instance, an agent should only be held responsible if she is eligible for normative assessment, meaning she is a mentally well grown-up, she contributed causally to the event, she knew what she was doing, she did it voluntarily, and what she did was wrong according to some set of norms. ${ }^{30}$ Of course, there is disagreement on the content of these conditions as well as how important each one of them is. The point is that we commonly use some set of conditions when ascribing responsibility and this can be seen as a way to make sure that responsibility is ascribed and distributed fairly.

The efficiency aim is about the way in which ascriptions and distributions of responsibility contribute to solving societal problems. Whether it be public health, poverty, education, or the environment-when discussing to whom we should ascribe responsibility and the question how responsibility should be distributed between different actors (individuals, governments, corporations, teachers, parents, and so forth) we do not merely care about what is fair, but also who is best apt at solving the problem.

To use this notion, my conclusion can be stated as follows. It is not fair to ascribe responsibility in the backward-looking sense, i.e., to blame individuals, for environmentally

\footnotetext{
29 A case in point could be the Swedish National Food Administration encouraging people to eat more fish, stating that people can eat as much farmed salmon as they want to without the risk of getting too much dioxin. The Swedish Consumer Agency, on the other hand, declares that farmed fish cannot be recommended from an environmental perspective.http://www.slv.se/templates/SLV_Page.aspx?id=14765\& epslanguage=SV\#fisk (In Swedish, accessed 10 Oct 2007) http://www.konsumentverket.se/mallar/ sv/fakta_recept.asp?IngCategoryId=1223\&lngArticleId=2319 (In Swedish, accessed 10 Oct 2007).

30 van de Poel et al. (Submitted).
} 
destructive actions unless they have reasonable alternatives and resources to act in environmentally friendly ways. However, it is fair to ascribe forward-looking responsibility to individuals, based on their capacity to contribute to solutions to environmental problems. Furthermore, a considerable share of forward-looking responsibility should be ascribed to governments and corporations because they can make the group of capable, hence responsible, individuals larger. The urge to ascribe forward-looking responsibility to institutional agents is motivated by the efficiency aim of responsibility distributions. Simply put, if we ascribe responsibility to governments and corporations we have a better chance of creating a society in which the opportunities to act in an environmentally friendly way increase.

Acknowledgment This research is part of the research program Moral Responsibility in R\&D Networks, which is supported by the Netherlands Organisation for Scientific Research (NWO) under grant number 36020-160.

Open Access This article is distributed under the terms of the Creative Commons Attribution Noncommercial License which permits any noncommercial use, distribution, and reproduction in any medium, provided the original author(s) and source are credited.

\section{References}

Aristotle Nicomachean Ethics The Internet Classics Archive, translated by W.D. Ross http://classics. mit.edu/Aristotle/nicomachaen.html.

Brewer, J., \& Trentmann, F. (Eds.) (2006). Consuming cultures, global perspectives: Historical trajectories, transnational changes. Oxford: Berg

Fischer, J. M., \& Ravizza, M. (1993a). Introduction. In J. M. Fischer \& M. Ravizza (Eds.), Perspectives on moral responsibility. Ithaca: Cornell University Press.

Garvey, J. (2008). The ethics of climate change. Right and wrong in a warming world. London: Continuum.

Goodin, R. E. (1986). Responsibilities. Philosophical Quarterly, 36, 50-56.

Green, M. (2005). Institutional responsibility for moral problems. In A. Kuper (Ed.), Global responsibilities who must deliver on human rights?. New York: Routledge.

IPCC. (2007). Fourth assessment report Climate change synthesis report http://www.ipcc.ch.

Jacobsen, E., \& Dulsrud, A. (2007). Will consumers save the world? the framing of political consumerism. Journal of Agricultural and Environmental Ethics, 20, 469-482.

Jamieson, D. (2007). When utilitarians should be virtue theorists. Utilitas, 19(2), 160-183.

Ladd, J. (1991). Bhopal: An essay on moral responsibility and civic virtue. Journal of Social Philosophy, 32(1), 73-91.

McKeon, R. (1957). The development and the significance of the concept of responsibility. Revue Internationale de Philosophie, XI(39), 3-32.

Micheletti, M. (2003). Political virtue and shopping: Individuals, consumerism, and collective action. New York: Palgrave Macmillan.

Miller, D. (2005). Distributing responsibilities. In A. Kuper (Ed.), Global responsibilities. Who must deliver on human rights?. New York: Routledge.

Nihlén Fahlquist, J. (2006a). Responsibility ascriptions and vision zero. Accident Analysis and Prevention, 38, 1113-1118.

Nihlén Fahlquist, J. (2006b). Responsibility ascriptions and public health problems. Who is responsible for obesity and lung cancer? Journal of Public Health, 14, 15-19.

Paul, E. F., Miller, F. D., \& Paul, J. (Eds.) (1999) Responsibility. Cambridge: Cambridge University Press.

Richardson, H. S. (1999). Institutionally divided moral responsibility. In E. F. Paul, F. D. Miller \& J. Paul (Eds.), Responsibility. Cambridge: Cambridge University Press.

Sassatelli, R. (2006). Virtue, responsibility and consumer choice: Framing critical consumerism. In J. Brewer \& F. Trentmann (Eds.), Consuming cultures, global perspectives: Historical trajectories transnational changes. Oxford: Berg.

Shue, H. (1988). Mediating duties. Ethics, 98(4), 687-704.

Sinnott-Armstrong, W. (2005). It's not my fault. In W. Sinnott-Armstrong \& R. B. Howarth (Eds.), Perspectives on climate change: Science, economics, politics, ethics. Amsterdam: Elsevier. 
Strawson P. (1962). Freedom and Resentment. In Proceedings of the British Academy 48. (Reprinted from Perspectives on moral responsibility, in by J. M. Fischer \& M. Ravizza, Eds., 1993, Cornell University Press: Ithaca.

Williams, G. (2008). Responsibility as a virtue. Ethical Theory and Moral Practice, 11(4), 455-470.

van de Poel, I., Nihlén Fahlquist, J., de Lima, T., Doorn, N., Royakkers, L., Zwart, S. Fairness and completeness in distributing responsibility: The case of engineering (Submitted).

Young, I. M. (2006). Responsibility and global justice: A social connection model. Social Philosophy and Policy, 23(1), 102-130. 